\title{
What is new in Genitourinary Pathology? Recent developments and highlights of the new 2016 World Health Organization classification of tumors of the urinary system and male genital organs
}

\author{
Daniel Abensur Athanazio ${ }^{1,2^{*}}$ (D) and Kiril Trpkov ${ }^{3}$
}

\begin{abstract}
The recently published 2016 World Health Organization (WHO) Classification of Tumors of the Urinary System and Male Genital Organs stems from the accumulated knowledge and data collected during the last 12 years, since the previous edition of the WHO "blue book" 2004.

The major changes in prostate pathology include the introduction of a novel grading system for prostate cancer (Grade Groups/International Society of Urological Pathology (ISUP) grades 1-5), the recognition of intraductal carcinoma as a new entity, and the terminological changes regarding the neuroendocrine prostatic neoplasms. In bladder and urothelial tract, within the spectrum of flat and non-invasive lesions, a newly introduced term "urothelial proliferation of uncertain malignant potential" replaced the term "urothelial hyperplasia", and the term "urothelial dysplasia" was better defined. A category of "invasive urothelial carcinoma with divergent differentiation" was introduced for tumors showing a component of "usual type" urothelial carcinoma combined with other morphologies. A new WHO/ISUP renal tumor grading system was recommended (Grade 1-4). The definition of renal papillary adenoma was modified and expanded to include papillary neoplasms measuring up to $1.5 \mathrm{~cm}$. Several new epithelial renal tumors were recognized as new entities including: hereditary leiomyomatosis and renal cell carcinoma (RCC) syndrome-associated RCC, succinate dehydrogenase-deficient RCC, tubulocystic RCC, acquired cystic disease-associated RCC, and clear cell papillary RCC.

In testis pathology, intratubular proliferations of testicular germ cell tumors were renamed as "germ cell neoplasia in-situ" (GCNIS), and the testicular neoplasms were divided into two main groups: derived from or unrelated to GCNIS. A major change in penile pathology was the introduction of a new classification of penile squamous cell carcinoma, based on the presence of human papillomavirus (HPV), which characterizes penile tumor subtypes as HPV-related or non-HPV-related. A similar distinction was introduced for the preneoplastic penile intraepithelial precursor lesion (PelN) into non-HPV related (differentiated PeIN) and HPV-related types (undifferentiated PeIN). In this review, we provide a summary and highlight the changes in the genitourinary pathology introduced by the 2016 WHO blue book, and we also discuss some recent developments that may impact the practice of genitourinary pathology in the near future.
\end{abstract}

Keywords: WHO, Classification, Genitourinary pathology, Prostate, Testis, Bladder, Kidney, Penis

\footnotetext{
* Correspondence: daa@ufba.br

${ }^{1}$ Faculdade de Medicina da Bahia, Departamento de Patologia e Medicina

Legal, Universidade Federal da Bahia, Praça XV de novembro, s/n—Largo do

Terreiro de Jesus, 40026010 Salvador, BA, Brazil

${ }^{2}$ Hospital Universitário Professor Edgard Santos (HUPES), R. Dr. Augusto Viana,

S/n-Canela, Salvador, BA 40110-060, Brazil

Full list of author information is available at the end of the article
} 


\section{Background}

The recently published 2016 World Health Organization (WHO) Classification of Tumors of the Urinary System and Male Genital Organs stems from the accumulated knowledge and data collected during the last 12 years, since the previous edition of the WHO "blue book" 2004. In this review, we provide a summary of the highlights and the changes in genitourinary pathology introduced by the 2016 WHO blue book, and we discuss some recent developments that may impact the practice of genitourinary pathology in the near future.

\section{Prostate}

\section{Novel prostate adenocarcinoma grading}

Over the last half a century, the Gleason grading system has been validated as a fundamental prognostic factor for patient outcome, on biopsy and on radical prostatectomy (RP), including biochemical failure, local recurrence and lymph node or distant metastasis. However, over the last two decades or so, many changes took place, including the introduction of a practice of thinneedle prostate biopsies, first as sextant, and then as systematic and extended prostate biopsies with site specific submission, with introduction and widespread use of immunohistochemistry ( $\mathrm{IHC}$ ), recognition of variants of adenocarcinoma, and the prognostic significance of certain morphologic patterns. These developments led to grading changes by the ISUP in 2005 (ISUP Modified Gleason System 2005) [1] and in 2014 (ISUP Consensus Conference on Gleason Grading 2014) [2]. The latest modifications from 2014 were incorporated in the WHO 2016 classification of prostate adenocarcinoma, which establishes a novel grading system based on stratification of the Gleason scores in Grade Groups/ISUP Grades 1 to 5 , corresponding to Gleason scores $\leq 6,3+4,4+3,8$ $(4+4,3+5,5+3)$ and $\geq 9$ [3]. The Grade Group 1 (Gleason scores $\leq 6$ ) is the lowest recommended grade as Gleason scores 2-5 are rarely used in the current practice and essentially pertain to the large majority of cases of Gleason score 6. It currently includes well differentiated and slow growing tumors that virtually have no potential of metastasizing and in many circumstances can be handled by active surveillance. It is currently recommended that this new grading system be reported in conjunction with the 2005 ISUP modified Gleason system. A recent study has validated the prognostic significance of the new grading system in a large multi- institutional cohort treated by radical prostatectomy and radiotherapy, using the biochemical recurrence as an outcome measure [4]. In another recent study from the UK, there was a strong correlation between the five grade groups and prostate cancer death [5].

The Consensus meeting of ISUP 2014 also added the following recommendations which are included in the
2016 WHO blue book and are confirmed by some more recent data $[2,4]$ :

- Glomeruloid glands and all cribriform gland morphologies should be assigned Gleason pattern 4 .

- Mucinous carcinoma should be graded on the basis of its background growth pattern instead of being classified automatically as pattern 4 .

Cribriform morphology has been associated with upgrading at RP when assigned in needle biopsies [6] and with cancer progression in RP specimens [7, 8], and it should be documented in needle biopsies when present. The current general rules in assigning and reporting Gleason scores in needle biopsy and RP mirror the recommendations from the 2005 ISUP consensus [1]. Although it has been previously recommended to quantify the amount of high grade carcinoma patterns 4 and 5 in needle biopsies and RP specimens, the reporting of percent pattern 4 is inconsistently done in clinical practice. In RP specimens, the amount of high grade component (Gleason patterns 4/5) has been previously confirmed to be an important predictor of survival [9]. However, it is now recommended to quantify the percentage pattern 4 in Gleason score $7(3+4$ or $4+3)$, when this is the highest grade in a needle biopsy or RP specimens. For example, a low percentage of pattern 4 in cases considered for active surveillance may influence a clinical decision for these patients to be selected for conservative management [10].

\section{Intraductal carcinoma}

Intraductal carcinoma has been recognized formally as a new entity in the 2016 WHO classifications, although this term and its morphology have been described previously [11]. It represents an intraepithelial spread or in-situ proliferation of acinar and ductal carcinoma, likely representing a late event in prostate cancer progression. It is defined by intraacinar/intraductal proliferation that may share some morphologic features with high grade prostatic intraepithelial neoplasia (HGPIN), but exhibits a much higher degree of architectural and cytologic atypia. Intraductal carcinoma should not be assigned a Gleason grade. It is rarelyan isolated finding in needle biopsy $(0.1-0.3 \%)$, and most of the cases are associated with high grade invasive carcinoma both in needle biopsies and RP. The frequency of intraductal carcinomas in RP specimens depends on the grade and the stage of tumors, ranging from 20 to $40 \%$ of all RP cases, while it is much lower in needle biopsies (about $3 \%)$. The presence of isolated intraductal carcinoma in a needle biopsy should be reported with a comment describing its strong association with high grade and high volume prostatic carcinoma, which likely was not 


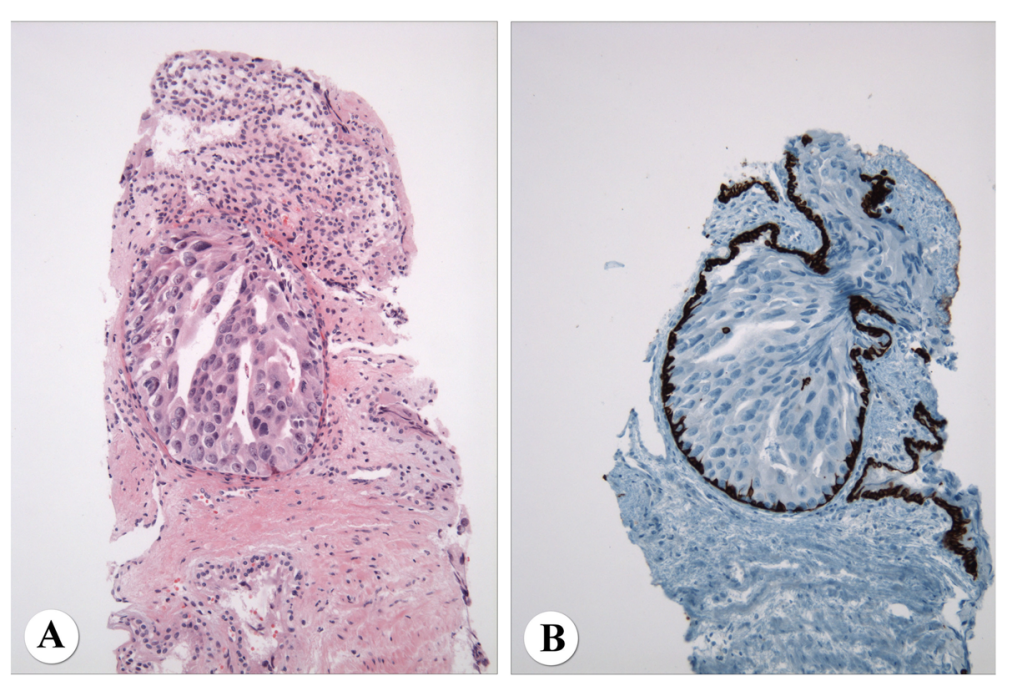

Fig. 1 a Intraductal carcinoma of prostate on needle core biopsy demonstrating significant cell atypia and cribriform growth. b Intraductal carcinoma shows preserved basal cell layer, highlighted by continuous staining for high molecular weight cytokeratin

sampled. If this is an isolated biopsy finding without an invasive carcinoma, a recommendation should be given for repeat biopsy, prior to definitive therapy,

The distinction between HGPIN, the only currently recognized form of prostate preneoplastic lesion, and intraductal carcinoma is crucial. Both show preservation of the basal cell layers, but intraductal carcinoma shows more commonly a dense cribriform or solid growth patterns, with frequent central comedonecrosis (Fig. 1a-b). The differential diagnosis in this setting may also include a solid growth pattern of invasive urothelial carcinoma. Another form of intraductal carcinoma demonstrates loose cribriform and micropapillary morphology, which should demonstrate high grade cytology with marked nuclear atypia (nuclei $\geq 6$ times higher than normal nuclei, or adjacent lymphocytes). In difficult cases, a diagnosis of atypical intraductal or cribriform growth may be used, with a comment that intraductal carcinoma cannot be ruled out. The expression of ERG and loss of PTEN in intraductal carcinoma have been advocated as useful supplementary tools, but technical difficulties in PTEN immunostaining currently preclude a recommendation for its widespread use.

\section{New variants of prostatic adenocarcinoma}

Two new variants of prostatic adenocarcinoma were included in the new blue book. The microcystic variant is characterized by acini that are 10 times the size of usual small acinar carcinoma, with rounded profiles and flat cell lining. The may show bland cytological features mimicking benign cystic atrophy. The assigned Gleason pattern is 3. Pleomorphic giant cell variant is exceptionally rare variant characterized by giant, bizarre, anaplastic cells with pleomorphic nuclei and lacking a spindle cell component. In some patients there is a history of prior hormonal or radiation therapy. The disease course is very aggressive.

\section{Variants of neuroendocrine tumors of the prostate}

Large cell neuroendocrine carcinoma, which is morphologically identical to its counterpart in the lung, has now been included in the 2016 WHO Classification of prostate tumors as a new variant [11]. Almost all cases were associated with hormonal treatment of prostate adenocarcinoma. Small cell carcinoma has been renamed small cell neuroendocrine carcinoma and carcinoid tumor has been now designated as well differentiated neuroendocrine tumor of prostate.

\section{Immunophenotype}

The novel and useful markers for prostate differentiation include prostein (P501S), a plasma membrane protein and NKX3.1, a homeobox-containing transcription factor, both highly sensitive for prostate adenocarcinoma [12]. These markers can be particularly useful in poorly differentiated prostate carcinoma cases demonstrating negative first line prostate markers, such as prostate-specific antigen (PSA) and prostate-specific acid phosphatase (PSAP), to separate them from urothelial carcinoma, for a diagnosis in a metastatic setting, or in tumors in which PSA and PSAP were significantly decreased due to androgen deprivation therapy.

\section{Bladder and urinary tract Urothelial tumor grading}

The new 2016 WHO blue book continued to endorse the classification of urothelial flat and papillary lesions proposed initially by ISUP in 1997, and adopted by the 
WHO in 2004, given the accumulated evidence comprised in the literature, which recognized its merits and advantages regarding the reproducibility and clinical significance when compared to WHO 1971 classification, which is currently used infrequently $[13,14]$. This classification provided uniform grading terminology, based on the observed cytologic and architectural abnormalities, and more specific criteria for various preneoplastic conditions and grades. It also eliminated the ambiguous "transitional" grades (grade $1-2$, grade 2-3) and maintained the existence of a category papillary urothelial neoplasm of low malignant potential (PUNLMP), which has a substantial potential for recurrence, but a very small risk of progression [15].

\section{Urothelial proliferation of uncertain malignant potential} In the diagnostic categories, the novel change is the replacement of the term "urothelial hyperplasia" by the term urothelial proliferation of uncertain malignant potential (UPUMP). This lesion represents a lesion with flat thickened urothelium with minimal or no cytological atypia; undulations are common, but true papillary fronds are lacking. The term is meant to represent the flat counterpart of the papillary urothelial neoplasm of low malignant potential (PUNLMP), which continues to be endorsed. The clinical relevance of UPUMP is not known, although it is possible that it represents a "shoulder lesion", commonly seen adjacent to true papillary neoplasms. This lesion can also be seen de novo, with uncertain clinical significance.

\section{Urothelial dysplasia}

This is a flat preneoplastic lesion with a degree of cytologic and architectural abnormalities that fall short of urothelial carcinoma in-situ (CIS) (Fig. 2a-b). It is often difficult to differentiate urothelial dysplasia from urothelium with reactive atypia or atypia of uncertain significance, particularly in settings of prior urothelial carcinoma, procedures, and use of intravesical therapy. This lesion is difficult to define precisely by morphology, primarily due to interobserver variability and lack of data on its relationship for development of subsequent CIS; however, the use of this diagnostic term is recommended. Strong and diffuse full thickness urothelial reactivity with cytokeratin 20 on IHC, as in urothelial CIS, may aid in establishing a diagnosis of urothelial dysplasia.

\section{Invasive urothelial carcinoma with divergent differentiation and urothelial carcinoma variants}

Invasive urothelial carcinomas demonstrate a broad variety of divergent differentiation, typically in combination with the "usual type" urothelial carcinoma, in about a third of the cases. The 2016 WHO blue book advocates the term infiltrating urothelial carcinoma with divergent differentiation and recommends that the amount of divergent histologies should be reported as a percentage [14]. It is believed that divergent differentiation is associated with poorer outcome, even though it has not been found to be a consistent independent risk factor in all studies and, at present, there is no direct relationship of the amount of divergent histology with the prognosis. The most common lines of divergent differentiations are

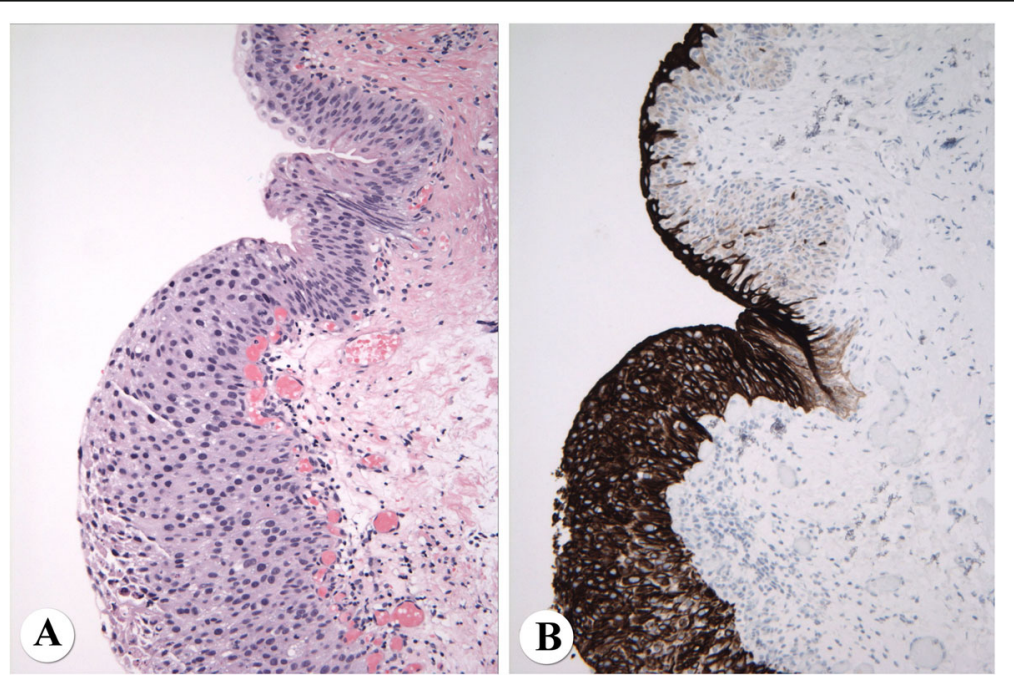

Fig. 2 a Urothelial dysplasia is a flat preneoplastic lesion demonstrating a degree of cytologic and architectural abnormalities that fall short of urothelial carcinoma in-situ. b Cytokeratin 20 exhibits diffuse full thickness reactivity in dysplastic urothelium (bottom), while in the normal urothelium only umbrella cells are positive (top) 


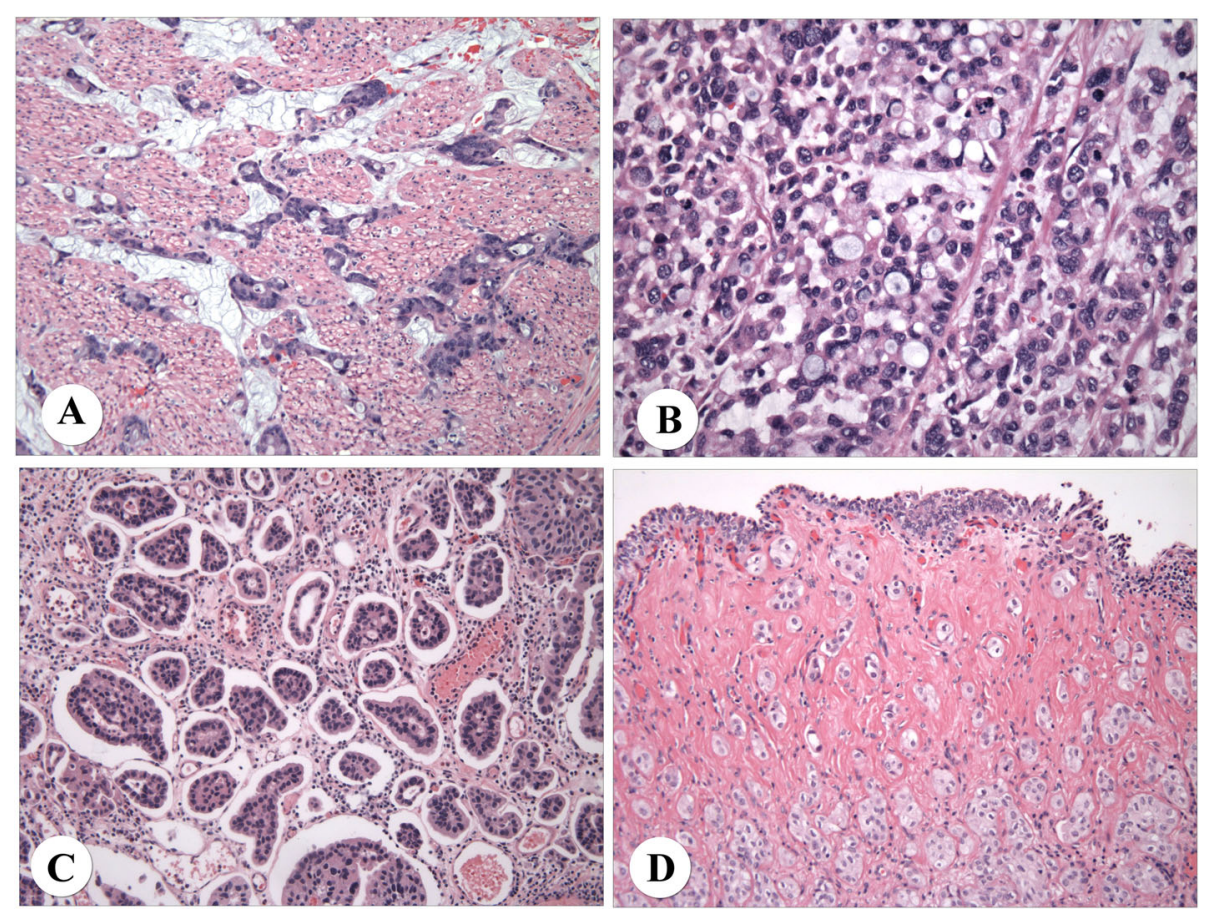

Fig. 3 a Glandular differentiation of mucinous type, demonstrating muscle invasion with extravasated mucin and free floating cells, including cells with signet-ring morphology. b Plasmacytoid carcinoma showing signet-ring cell morphology without extracellular mucin or gland formation. c Micropapillary carcinoma showing numerous micropapillary and ring formations floating in lacunar spaces. $\mathbf{d}$ Nested carcinoma is composed of small nests with deceptively bland cytology demonstrating extensive invasion into lamina propria

squamous (about $40 \%$ of all cases) and glandular (about $20 \%)$. The novel variants of urothelial carcinoma include glandular neoplasms of enteric type, morphogically identical to the colonic counterpart and the mucinous type, characterized with extravasated mucin and free floating cells, including cells with signet ring morphology (Fig. 3a). The typical signet ring cell carcinoma however shows no association with extracellular mucin or gland formation and usually coexists with a predominant plasmacytoid morphology (Fig. 3b). Distinction between enteric type differentiation and primary colonic adenocarcinoma can be challenging, because divergent enteric differentiation of urothelial carcinomas is associated with gain of CDX2 and cytokeratin 20 expression, and loss of GATA3, p63 and high molecular weight cytokeratin. In this setting, as recommended by ISUP, the most useful marker is betacatenin which shows nuclear reactivity in $90 \%$ of colonic adenocarcinomas and $90 \%$ membrane reactivity in over $90 \%$ of primary bladder adenocarcinomas or urothelial carcinomas with glandular differentiation [16]. Micropapillary, plasmacytoid, nested and poorly differentiated variants of urothelial carcinoma are associated with more aggressive behavior and poor outcome (Fig. 3c-d). Nested, large nested and microcystic variants of urothelial carcinoma are also important because they demonstrate deceptively bland cytological morphology and may be misdiagnosed as benign lesions, although they are inherently aggressive. Other morphologies include trophoblastic, lymphoepithelioma-like, giant cell, lipid-rich, clear cell and sarcomatoid, which can sometimes appear as variable patterns of divergent differentiation in urothelial carcinoma.

\section{Tumors of Müllerian origin}

A new category of bladder neoplasms comprise the tumors of Müllerian origin which originate primarily from the bladder wall or the adjacent soft tissues, likely from foci of endometriosis or müllerianosis [14]. It is unlikely that these tumors are of urothelial origin. They typically show tubulocystic, papillary or diffuse morphology. The most common types are clear cell carcinoma and endometrioid carcinoma, both of which share overlapping morphologic and immunophenotypical features with their ovarian counterparts.

\section{Tumors arising in a bladder diverticulum}

Another new neoplastic category represents the tumors arising in a bladder diverticulum [14]. About $14 \%$ of all bladder diverticula will harbor a malignant tumor and these tumors comprise about $1 \%$ of all bladder cancers. About half of the tumors are non-invasive, while the other half are invasive; all tumors are mostly of usual urothelial type. Since the diverticula lack the muscularis 
propria layer, the pathologic staging system in this setting differs from others carcinomas of the bladder, as pT2 stage does not exist.

\section{Neuroendocrine tumors of bladder}

Similar to the prostate, small cell carcinoma has been renamed small cell neuroendocrine carcinoma and carcinoid tumor has been named well differentiated neuroendocrine tumor of bladder. The entity large cell neuroendocrine carcinoma, has now also been included in the 2016 WHO Classification of bladder tumors as a new variant.

\section{Kidney}

\section{Changes pertaining to existing renal tumor types}

The ISUP Vancouver consensus conference in 2012 was the basis for the updates of the 2016 WHO renal tumor classification [17]. Multilocular cystic renal cell carcinoma (RCC) has been renamed multilocular cystic renal neoplasm of low malignant potential. These are indolent tumors which resemble low grade clear cell RCC with extensive cyst formation, but without the expansive nodules. Although traditionally papillary RCC has been divided into types 1 and 2, it is becoming apparent that "type 2 papillary RCC" may not constitute a single entity, but rather represent a morphology seen in a variety of neoplasms, including, for example, Xp11 translocation RCC and collecting duct RCC, as acknowledged in the 2016 WHO renal tumor classification. It is conceivable that type 2 papillary RCC is an umbrella category comprising tumors with similar morphology, but distinct molecular backgrounds. In addition, there is papillary RCC with eosinophilic (oncocytic) cytoplasm (oncocytic papillary RCC variant), which is included in type 2 papillary RCC in the new classification, till it is better characterized. The size criterion for papillary adenoma, previously defined as papillary tumor $\leq 0.5 \mathrm{~cm}$, has been changed and expanded to include all unencapsulated tumors of lower grade with papillary or tubular morphology up to $1.5 \mathrm{~cm}$ in size, because they essentially have no metastatic potential. Finding these types of relatively common tumors in potential donor kidneys should not be a contraindication for allograft transplantation. Mixed epithelial and stromal tumors (MEST) has been now been defined to include a broad spectrum of tumors from almost exclusively cystic at one end (cystic nephroma), to tumors that are predominantly solid at the other end (classical MEST). In contrast to adult cystic nephroma, pediatric cystic nephroma represents a distinct entity characterized by DICER1 mutation. Xp11 translocation carcinoma has been renamed MiT family translocation RCC to include not only TFE3 translocation tumors, but also TFEB tumors. Carcinoma of the collecting duct of Bellini has been renamed collecting duct RCC. Carcinoid of the kidney, most of which have poor prognosis, has been renamed well differentiated neuroendocrine tumor of kidney, and placed within the spectrum of renal endocrine tumors, which include small and large cell neuroendocrine carcinomas and paragangliomas (extrarenal pheochromocytoma).

\section{New renal tumor entities}

Renal cell carcinomas are subtyped on the basis of their morphologic architectural and cytologic features, anatomic location or the association with specific disease, molecular alterations or familial syndromes. Many unclassified RCC in the past can now be correctly diagnosed or reclassified using the accumulated data and knowledge, along with proper molecular testing, which is increasingly becoming available in selected reference centers.

Several entities are recognized as new RCC subtypes in the WHO 2016 blue book [18].

\section{Hereditary leiomyomatosis and renal cell carcinoma (RCC) syndrome associated-RCC}

Hereditary leiomyomatosis and renal cancer syndrome (HLRCC) is an autosomal dominant disorder characterized by inherited predisposition to uterine and cutaneous leiomyomas and renal cell carcinoma. It is characterized by inactivating germ-line mutation in the fumarate hydratase $(F H)$ gene, which is located at 1q42.3-q43 and codes for an enzyme involved in the tricarboxylic acid cycle, which catalyzes and hydrates fumarate to form malate. HLRCC associated -RCC are morphologically characterized by frequent papillary architecture, abundant eosinophilic cytoplasm, large nuclei and very prominent nucleoli ("cherry-red nucleoli") with perinucleolar clearing, that resemble viral inclusions [19] (Fig. 4a-b). FH deficiency can be demonstrated by the absence of staining for FH on IHC. Recent data indicate that the spectrum of so called "FH-deficient $R C C$ " may be broader and may include tumors with papillary and other morphologies, not currently considered to fit the strict definition of HLRCC syndrome associatedRCC [20, 21]. It is important that these tumors are identified because they show aggressive behavior and poor outcome and may run in families.

\section{Succinate dehydrogenase-deficient RCC}

SDH-deficient renal carcinoma represents a distinct and rare renal neoplasm, which is defined by loss of IHC staining for SDHB, which indicates mitochondrial complex II dysfunction [22, 23]. Great majority of SDHdeficient renal tumors demonstrate typical appearances at least focally with uniform low-grade cytology, cytoplasmic vacuoles, eosinophilic or flocculent (not oncocytic) cytoplasm, focal cystic change, and solid to lobulated growth with peripherally entrapped renal tubules (Fig. 4c-d). In tumors exhibiting low-grade nuclear features, metastasis 


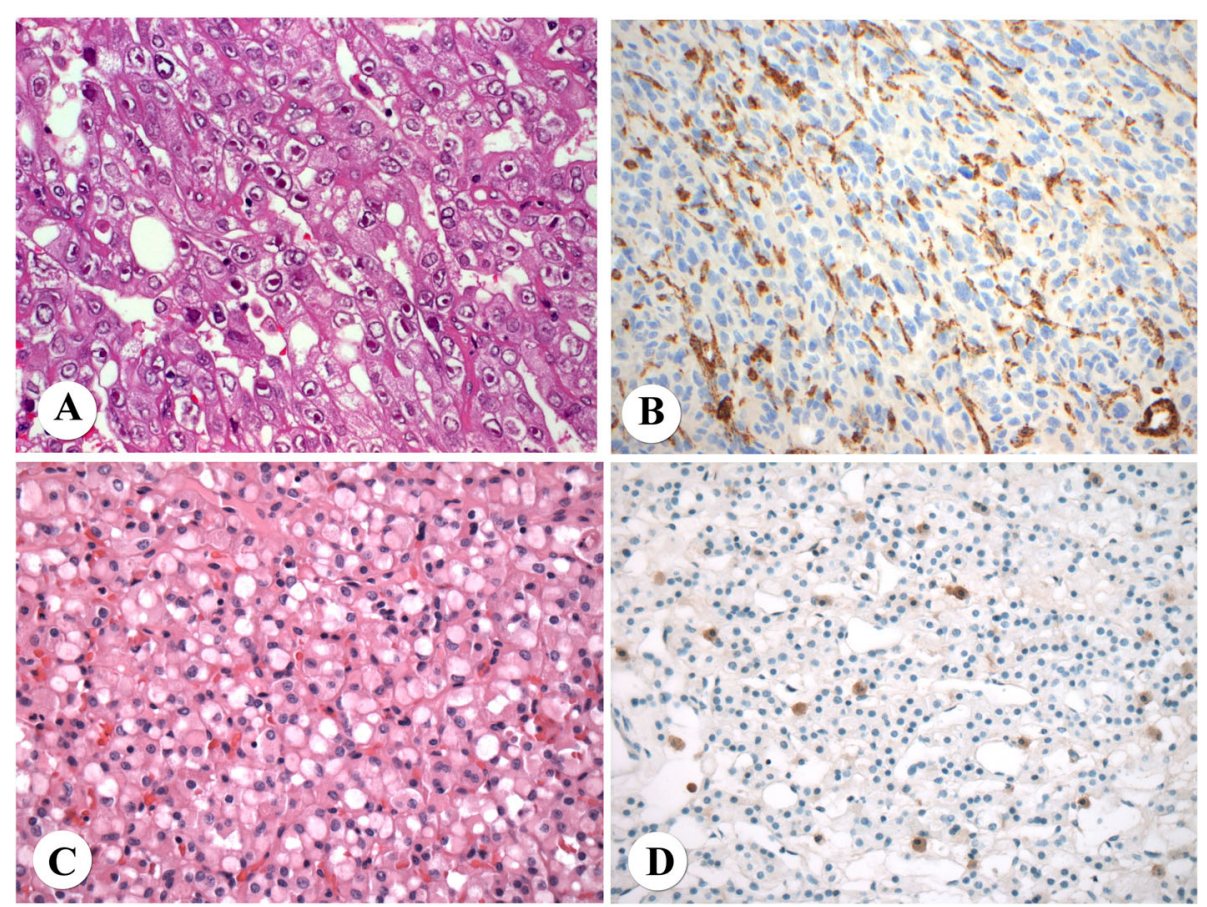

Fig. 4 a HLRCC syndrome-associated RCC shows abundant eosinophilic cytoplasm, large nuclei and very prominent nucleoli with perinucleolar halos that resemble viral inclusions. $\mathbf{b}$ FH deficiency can be demonstrated by the lack of staining for FH on immunohistochemistry (only the background stromal cells are FH positive). c Typical appearances of SDH-deficient RCC with uniform low-grade cytology, cytoplasmic vacuoles, and eosinophilic or flocculent cytoplasm. d All SDH-deficient RCC show negative staining for SDHB on IHC; note the positive mast cells, which are often seen in the background

is unusual, but those demonstrating high grade cytology, coagulative necrosis or sarcomatoid transformation, demonstrate potential for metastatic disease, often after a prolonged period. The patients with these tumors also have increased risk of developing paragangliomas and gastrointestinal stromal tumors. Great majority of the reported cases have been associated with germline mutations of the $S D H$ genes.

\section{Tubulocystic RCC}

Tubulocystic RCC is composed of variable-sized cysts, which provide a spongy cut surface on gross examination. The key feature is the morphology of variable-sized tubules and cysts which are lined by a single layer of flat or hobnail cell with prominent nucleoli (ISUP/WHO grade 3 ) and separated by thin fibrous septa. This is also a rare tumor, which accounts for less than $1 \%$ of all kidney tumors. It shows predilection for male patients. Only a small minority of reported cases showed metastatic behavior. As cytogenetic (trisomy 7 and 17, loss of Y) and immunoprofile (CK7, CD10, AMACR all positive) similarities have been found with papillary $R C C$, they may be related to papillary $\mathrm{RCC}$. Of note, the presence of tubulocystic morphology admixed with other architectural patterns (or areas of dedifferentiation), argues strongly against the diagnosis of tubulocystic RCC and may indicate other tumor type (e.g. FH-deficient RCC).

\section{Acquired cystic disease associated RCC}

Acquired cystic disease associated RCC typically arises in end-stage kidneys showing acquired cystic disease, often after prolonged dialysis. Although this is the most common subtype of RCC arising in end-stage renal disease and acquired cystic disease, about $2 / 3$ of epithelial malignancies in end-stage RCC fall into other diagnostic categories. Acquired cystic disease associated RCC demonstrate a morphologic spectrum of cribriform, microcystic and sieve-like growth, with invariable deposits of calcium oxalate crystals, which are characteristic. The cells may show eosinophilic or clear cytoplasm and the nucleoli are prominent. Cytokeratin 7 is typically negative. Most tumors show an indolent behavior.

\section{Clear cell papillary RCC}

Clear cell papillary RCC is probably the most common type of the newly recognized entities. It is a low-grade neoplasm composed by clear epithelial cells arranged in tubules or papillae with a linear nuclear alignment away from the basement membrane, with subnuclear vacuoles (piano key appearance). These are indolent tumors that should be distinguished from clear cell RCC. Strong positivity for cytokeratin 7 is a useful tool, as well as CAIX "cup-shaped" reactivity; CD10 is either negative or only focally positive. The stroma may show variable amounts of fibrous or smooth muscle bundles. Renal 
angiomyoadenomatous tumor (RAT) is another, now obsolete term for this renal tumor. Recent findings indicate that this entity should not be overdiagnosed, because there are cases with mixed features between clear cell papillary RCC and clear cell conventional RCC (both morphologic or by immunophenotype), and there are other similar tumors, characterized by hotspot mutations in TCEB1 $[24,25]$.

\section{Emerging renal entities}

The ISUP 2012 renal tumor classification included a category of emerging renal entities, acknowledging that more data on morphology, immunophenotype and outcome are needed for their formal recognition. This category initially included thyroid-like follicular RCC, $A L K$ rearrangement-associated RCC and SDH-deficient RCC, the latter now recognized as a new type by the WHO. Other emerging tumors include RCC with angioleiomyomatous stroma, some of which show TCEB1 hotspot mutations and may represent a distinct subtype [25], while some examples are believed to be in the spectrum of clear cell papillary RCC. A category of RCC in neuroblastoma survivors was removed from the 2016 WHO classification, as some of these clearly belong to the MiTF family translocation RCC, and some are difficult to classify [26].

Eosinophilic, solid and cystic renal cell carcinoma (ESC-RCC) is another emerging entity that has been described recently. ESC-RCC occurs exclusively in female patients with and without associated tuberous sclerosis complex [27, 28]. Most tumors show mixed solid and cystic gross appearance, and on microscopy they demonstrate solid or compact nested growth of eosinophilic cells admixed with cysts lined by with hobnailed cells. A distinctive feature is the presence of coarse cytoplasmic stippling (basophilic granules) and intracytoplasmic globules. Immunostaining typically shows a cytokeratin
20+, cytokeratin7-profile. These tumors demonstrate indolent behavior.

\section{Grading of renal tumors}

2016 WHO blue book recommended adoption of a novel grading system called ISUP/WHO grading system [29]. It simplifies and improves upon the previously applied Fuhrman system, because it is based on the nucleolar appearances and size, avoiding the requirement of nuclear size estimation. ISUP/WHO is a four-tiered grading system, defined as follows:

Grade 1: Inconspicuous or absent nucleoli at x400 magnification.

Grade 2: Nucleoli are conspicuous at $x 400 x$

magnification and visible but not prominent at x100 magnification.

Grade 3: Nucleoli are conspicuous at x100

magnification.

Grade 4: Extreme nuclear pleomorphism,

multinucleated giant cell and/or rabdoid/sarcomatoid morphology.

To date, this system has been validated for clear cell and papillary RCCs. This grading system should not be applied to chromophobe RCC, and has not been validated for other less common tumor types.

\section{Testis}

The 2016 WHO blue book recommended the term germ cell neoplasia in-situ (GCNIS) to unify the terminology of undifferentiated intratubular neoplasia, previously known as carcinoma in-situ or intratubular germ cell neoplasia, unclassified (IGCNU) (Fig. 5) [30]. Other variants of intratubular neoplasia demonstrating luminal space-filling features should be designated with the prefix intratubular, followed by the respective neoplastic
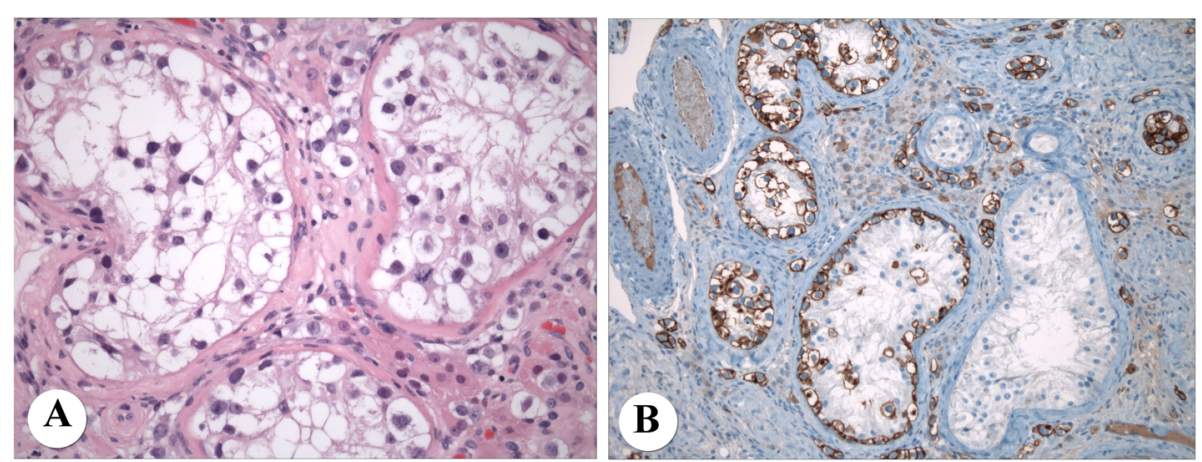

Fig. 5 a GCNIS is a proliferation of intratubular malignant germ cells with morphologic and immunohistochemical features of seminoma cells arising in the spermatogonial niche; note also the presence of intertubular infiltrating seminoma. $\mathbf{b} \| \mathrm{HC}$ by C-kit (CD117) highlights the GCNIS in the tubules and in the interstitium 
component (e.g. intratubular seminoma or intratubular embryonal carcinoma). GCNIS is a proliferation of intratubular malignant germ cells with morphologic and IHC features of seminoma cells arising in the spermatogonial niche. GCNIS should be distinguished from maturationdelayed germ cells, which are common in patients with sex development disorders, and are more diffusely distributed and centrally located within seminiferous tubules, and lack expression of KIT ligand (stem cell factor).

Germ cell tumors are now broadly separated into two main groups: derived from GCNIS or unrelated to GCNIS. Those derived from GCNIS share the features of abnormal testicular development in the background, such as impaired spermatogenesis, tubular atrophy, peritubular sclerosis, interstitial expansion, and microlithiasis. These include: seminoma, embryonal carcinoma, yolk sac tumor postpubertal type, trophoblastic tumors, teratoma postpubertal type and teratoma with somatictype malignancy. Teratoma and yolk sac tumor may belong to both groups (related to or unrelated to GCNIS). Thus, GCNIS-derived tumors are designated postpubertal and those that are unrelated to CGNIS are labeled prepubertal. The new classification also acknowledges that the genetic backgrounds of teratoma and yolk sac tumor are different in its pre- and postpuberal forms and deserves separation into distinct entities. In addition to the presence or absence of GCNIS, prepubertal teratomas and yolk sac tumors lack 12p amplification and do not occur in malformed testes. Prepubertal teratoma and yolk sac tumor, or mixed neoplasm composed by both, share excellent prognosis [31]. Postpubertal teratoma comprises the previous "mature and immature teratoma" categories and demonstrates a metastatic rate of about $30 \%$. The presence or quantification of the dysplastic or immature component does not need to be specified if there are no expansive nodules larger than one low power field (x 4 objective, $5 \mathrm{~mm}$ in diameter). In addition to placental site trophoblastic tumor, the genuine non-choriocarcinomatous trophoblastic tumors now include epithelioid trophoblastic tumors and cystic trophoblastic tumors. These are most common in metastatic lesions or post-chemotherapy.

The tumors unrelated to GCNIS are a more heterogeneous group which include spermatocytic tumor (a new term for spermatocytic seminoma), teratoma prepubertal type (including dermoid cyst, epidermoid cyst and monodermal teratoma-well differentiated neuroendocrine tumor), yolk sac tumor prepubertal type, and mixed teratoma and yolk sac tumor, prepubertal type. The low grade neuroendocrine tumor has a metastatic rate that is lower than $15 \%$. They may be pure $(\sim 70 \%$ of all cases) or mixed with other teratoma components.
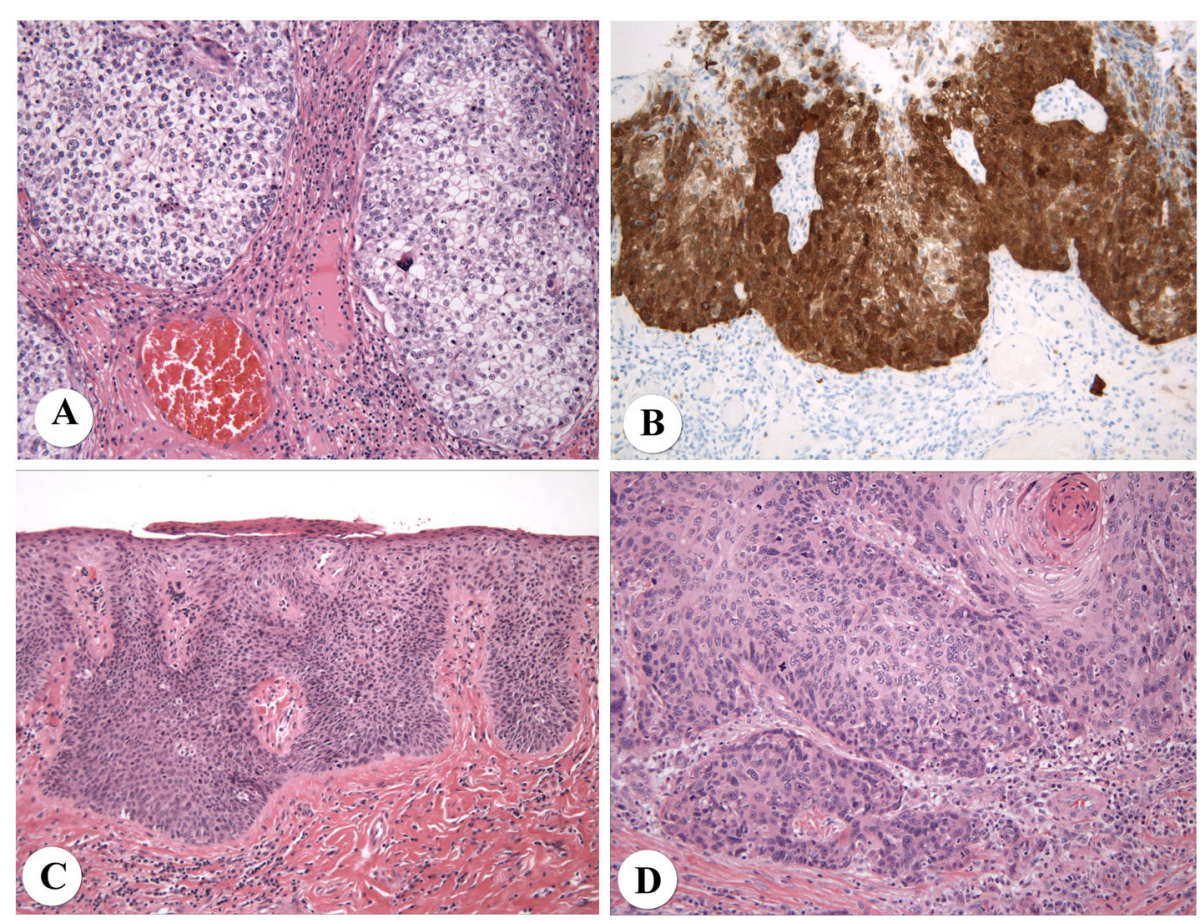

Fig. 6 a Clear cell carcinoma is a very rare penile carcinoma, which represents an example of HPV-related penile carcinoma. b Clear cell carcinoma demonstrates diffuse and strong staining for p16 on IHC. c Penile intraepithelial neoplasia (PeIN), a preneoplastic precursor lesion with dysplastic epithelial changes with non-HPV related (differentiated) PelN features. $\mathbf{d}$ Squamous cell carcinoma of penis, Grade 2, is comprised of poorly differentiated areas with focal squamous differentiation (keratohyaline pearl) 
Minor changes are introduced in the sex cord-stromal tumor category. Sclerosing Sertoli cell tumor is now included in the Sertoli cell tumor, not otherwise specified, due to the similar genetic background. However, it is recommended that term sclerosing should still be used to designate tumor containing more than $50 \%$ hipocellular fibrous stroma, because these have a more favorable prognosis. Intratubular large cell hyalinizing Sertoli tumor is a new entity associated with Peutz-Jegers syndrome which shows a characteristic mutation of STK1 gene. Gonadoblastoma currently remains the sole entity in the mixed germ cell-sex cord-stromal category. In the mesothelial tumor section, the benign mesothelioma category was abolished. Well differentiated papillary mesothelioma is considered to be an indolent variant of mesothelioma. The term cystic mesothelioma no longer exists and those lesions should be considered either as non-neoplastic mesothelial cysts or as variants of conventional mesothelioma.

\section{Penis}

The previous penile classification was strictly morphological and the 2016 WHO classification, in addition to the clinicopathologic features, takes into consideration the relationship of the neoplasm to the human papilloma virus (HPV) [32]. The great majority of penile malignant tumors are squamous cell carcinomas (SCC), which are now divided into two main groups, non-HPV related: usual, pseudohyperplastic, pseudoglandular, verrucouswith the cuniculatum variant, papillary, adenosquamous and sarcomatoid) and HPV-related: basaloid and warty/ condilomatous, and other rare morphologies, such as warty-basaloid, papillary-basaloid, clear cell (Fig. 6a-b), lymphoepithelioma-like and medullary. Penile intraepithelial neoplasia (PeIN), a preneoplastc precursor lesion with dysplastic epithelial changes, is also grouped into non-HPV related (differentiated PeIN) (Fig. 6c) and HPV-related or undifferentiated (basaloid, warty or basaloid-warty) type [33]. A three tiered WHO/ISUP grading system is now recommended for SCC: Welldifferentiated SCC, Grade 1, with cytological features of normal squamous epithelium, growing in large sheets or irregular nests with little intervening stroma; Grade 2 SCC, comprised of cases showing intermediate features between Grade 1 and 3 (Fig. 6d); and poorly differentiated carcinoma, Grade 3, showing smaller tumor nests with poor keratinization and difficult to find pearls, irregular infiltrative and polymorphic growth, frequent mitoses and marked stromal reaction.

\section{Conclusions}

The 2016 World Health Organization (WHO) Classification of Tumors of the Urinary System and Male Genital Organs reflects an improved understanding and knowledge of the morphologic types and variants of urologic tumors. It also provides novel insights in the molecular and genetic background and biological behavior of the genitourinary neoplasms. It is anticipated that the adoption of the new diagnostic categories and grading systems will increase the diagnostic reproducibility and clinicopathological correlation and prognostication, leading to a better patient care worldwide.

\section{Acknowledgements}

The authors are grateful to Brenda Jensen for her assistance on reference management.

\section{Funding}

Not applicable.

Availability of data and materials

Not applicable.

\section{Authors' contributions}

DAA drafted the manuscript. KT critically reviewed for intellectual content. Both authors read and approved the final manuscript.

\section{Competing interests}

The authors declare that they have no competing interests.

Consent for publication

Not applicable.

Ethics approval and consent to participate

Not applicable.

\section{Author details}

${ }^{1}$ Faculdade de Medicina da Bahia, Departamento de Patologia e Medicina Legal, Universidade Federal da Bahia, Praça XV de novembro, s/n—Largo do Terreiro de Jesus, 40026010 Salvador, BA, Brazil. ${ }^{2}$ Hospital Universitário Professor Edgard Santos (HUPES), R. Dr. Augusto Viana, S/n—Canela, Salvador, BA 40110-060, Brazil. ${ }^{3}$ Department of Pathology and Laboratory Medicine, Calgary Laboratory Services and University of Calgary, Rockyview General Hospital, 700714 st, Calgary T2V 1P9, AB, Canada.

Received: 6 July 2016 Accepted: 25 October 2016

Published online: 24 November 2016

\section{References}

1. Epstein Jl, Allsbrook Jr WC, Amin MB, Egevad LL. The 2005 International Society of Urological Pathology (ISUP) consensus conference on gleason grading of prostatic carcinoma. Am J Surg Pathol. 2005;29(9):1228-42.

2. Epstein JI, Egevad L, Amin MB, Delahunt B, Srigley JR, Humphrey PA, Grading C. The 2014 International Society of Urological Pathology (ISUP) consensus conference on gleason grading of prostatic carcinoma: definition of grading patterns and proposal for a new grading system. Am J Surg Pathol. 2016:40(2):244-52.

3. Pierorazio PM, Walsh PC, Partin AW, Epstein JI. Prognostic Gleason grade grouping: data based on the modified Gleason scoring system. BJU Int. 2013;111(5):753-60.

4. Epstein Jl, Zelefsky MJ, Sjoberg DD, Nelson JB, Egevad L, Magi-Galluzzi C, Vickers AJ, Parwani AV, Reuter VE, Fine SW, et al. A Contemporary Prostate Cancer Grading System: A Validated Alternative to the Gleason Score. Eur Urol. 2016;69(3):428-35.

5. Berney DM, Beltran L, Fisher G, North BV, Greenberg D, Moller H, Soosay G, Scardino P, Cuzick J. Validation of a contemporary prostate cancer grading system using prostate cancer death as outcome. Br J Cancer. 2016;114(10): 1078-83.

6. Keefe DT, Schieda N, El Hallani S, Breau RH, Morash C, Robertson SJ, Mai KT, Belanger EC, Flood TA. Cribriform morphology predicts upstaging after radical prostatectomy in patients with Gleason score $3+4=7$ prostate cancer at transrectal ultrasound (TRUS)-guided needle biopsy. Virchows Arch. 2015;467(4):437-42. 
7. Kweldam CF, Wildhagen MF, Steyerberg EW, Bangma $\mathrm{CH}$, van der Kwast $\mathrm{TH}$, van Leenders GJ. Cribriform growth is highly predictive for postoperative metastasis and disease-specific death in Gleason score 7 prostate cancer. Mod Pathol. 2015;28(3):457-64.

8. Dong F, Yang P, Wang C, Wu S, Xiao Y, McDougal WS, Young RH, Wu CL. Architectural heterogeneity and cribriform pattern predict adverse clinical outcome for Gleason grade 4 prostatic adenocarcinoma. Am J Surg Pathol. 2013:37(12):1855-61.

9. Cheng L, Davidson DD, Lin H, Koch MO. Percentage of Gleason pattern 4 and 5 predicts survival after radical prostatectomy. Cancer. 2007;110(9):1967-72

10. Morash C, Tey R, Agbassi C, Klotz L, McGowan T, Srigley J, Evans A. Active surveillance for the management of localized prostate cancer: Guideline recommendations. Can Urol Assoc J. 2015;9(5-6):171-8.

11. Moch H, Humphrey PA, Ulbright TM, Reuter VE. Chapter 3 Tumours of the prostate. In: WHO Classification of Tumours of the urinary system and male genital organs. Lyon: IARC; 2016. p. 135-83.

12. Amin MB, Epstein Jl, Ulbright TM, Humphrey PA, Egevad L, Montironi R, Grignon D, Trpkov K, Lopez-Beltran A, Zhou M, et al. Best Practices Recommendations in the Application of Immunohistochemistry in Urologic Pathology: Report From the International Society of Urological Pathology Consensus Conference. Am J Surg Pathol. 2014;38(8):1017-22.

13. Eble JN, Sauter G, Epstein JI, Sesterhenn IA. WHO Classification of Tumours. Pathology and genetics of tumours of the urinary system and male genital organs, vol. 7. 3rd ed. Lyon: IARC; 2004.

14. Moch H, Humphrey PA, Ulbright TM, Reuter VE. Chapter 2 Tumours of the urinary tract. In: WHO Classification of Tumours of the Urinary system and male genital organs. Lyon: IARC; 2016. p. 77-133.

15. Maxwell JP, Wang C, Wiebe N, Yilmaz A, Trpkov K. Long-term outcome of primary Papillary Urothelial Neoplasm of Low Malignant Potential (PUNLMP) including PUNLMP with inverted growth. Diagn Pathol. 2015;10(1):3.

16. Amin MB, Trpkov K, Lopez-Beltran A, Grignon D, Members of the IliDUPG. Best practices recommendations in the application of immunohistochemistry in the bladder lesions: report from the International Society of Urologic Pathology consensus conference. Am J Surg Pathol. 2014;38(8):e20-34.

17. Srigley JR, Delahunt B, Eble JN, Egevad L, Epstein Jl, Grignon D, Hes O, Moch H, Montironi R, Tickoo SK, et al. The International Society of Urological Pathology (ISUP) Vancouver Classification of Renal Neoplasia. Am J Surg Pathol. 2013;37(10):1469-89.

18. Moch H, Humphrey PA, Ulbright TM, Reuter VE. Chapter 1 Tumours of the kidney. In: WHO Classification of Tumours of the urinary system and male genital organs. Volume 4th Edition. Lyon: IARC; 2016. p. 11-76.

19. Merino MJ, Torres-Cabala C, Pinto P, Linehan WM. The morphologic spectrum of kidney tumors in hereditary leiomyomatosis and renal cell carcinoma (HLRCC) syndrome. Am J Surg Pathol. 2007;31(10):1578-85.

20. Chen YB, Brannon AR, Toubaji A, Dudas ME, Won HH, Al-Ahmadie HA, Fine SW, Gopalan A, Frizzell N, Voss MH, et al. Hereditary leiomyomatosis and renal cell carcinoma syndrome-associated renal cancer: recognition of the syndrome by pathologic features and the utility of detecting aberrant succination by immunohistochemistry. Am J Surg Pathol. 2014;38(5):627-37.

21. Trpkov K, Hes O, Agaimy A, Bonert M, Martinek P, Magi-Galluzzi C, Kristiansen G, Luders C, Nesi G, Comperat E, et al. Fumarate Hydratasedeficient Renal Cell Carcinoma Is Strongly Correlated With Fumarate Hydratase Mutation and Hereditary Leiomyomatosis and Renal Cell Carcinoma Syndrome. Am J Surg Pathol. 2016;40(7):865-75.

22. Gill AJ. Succinate dehydrogenase (SDH) and mitochondrial driven neoplasia. Pathology. 2012;44(4):285-92.

23. Gill AJ, Hes O, Papathomas T, Sedivcova M, Tan PH, Agaimy A, Andresen PA, Kedziora A, Clarkson A, Toon CW, et al. Succinate Dehydrogenase (SDH)deficient Renal Carcinoma: A Morphologically Distinct Entity: A Clinicopathologic Series of 36 Tumors From 27 Patients. Am J Surg Pathol. 2014:38(12):1588-602.

24. Dhakal HP, McKenney JK, Khor LY, Reynolds JP, Magi-Galluzzi C, Przybycin CG. Renal Neoplasms With Overlapping Features of Clear Cell Renal Cell Carcinoma and Clear Cell Papillary Renal Cell Carcinoma: A Clinicopathologic Study of 37 Cases From a Single Institution. Am J Surg Pathol. 2016:40(2):141-54.

25. Hakimi AA, Tickoo SK, Jacobsen A, Sarungbam J, Sfakianos JP, Sato Y, Morikawa T, Kume H, Fukayama M, Homma Y, et al. TCEB1-mutated renal cell carcinoma: a distinct genomic and morphological subtype. Mod Pathol. 2015;28(6):845-53.
26. Falzarano SM, McKenney JK, Montironi R, Eble JN, Osunkoya AO, Guo J, Zhou S, Xiao H, Dhanasekaran SM, Shukla S, et al. Renal Cell Carcinoma Occurring in Patients With Prior Neuroblastoma: A Heterogenous Group of Neoplasms. Am J Surg Pathol. 2016;40(7):989-97.

27. Guo J, Tretiakova MS, Troxell ML, Osunkoya AO, Fadare O, Sangoi AR, Shen SS, Lopez-Beltran A, Mehra R, Heider A, et al. Tuberous Sclerosis-associated Renal Cell Carcinoma: A Clinicopathologic Study of 57 Separate Carcinomas in 18 Patients. Am J Surg Pathol. 2014;38(11):1457-67.

28. Trpkov K, Hes O, Bonert M, Lopez Jl, Bonsib SM, Nesi G, Comperat E, Sibony M, Berney DM, Martinek P, et al. Eosinophilic, Solid, and Cystic Renal Cell Carcinoma: Clinicopathologic Study of 16 Unique, Sporadic Neoplasms Occurring in Women. Am J Surg Pathol. 2016;40(1):60-71.

29. Delahunt B, McKenney JK, Lohse CM, Leibovich BC, Thompson RH, Boorjian SA Cheville JC. A novel grading system for clear cell renal cell carcinoma incorporating tumor necrosis. Am J Surg Pathol. 2013;37(3):311-22.

30. Moch H, Humphrey PA, Ulbright TM, Reuter VE. Chapter 4 Tumours of the testis and paratesticular tissue. In: Who Classification of tumours of the urniary system and Male genital organs. Lyon: IARC; 2016. p. 185-257.

31. Ulbright TM, Young RH. Testicular and paratesticular tumors and tumor-like lesions in the first 2 decades. Semin Diagn Pathol. 2014;31(5):323-81.

32. Moch H, Humphrey PA, Ulbright TM, Reuter VE. Chapter 5 Tumours of the penis. In: WHO Classification of tumours of the urinary system and male genital organs. Lyon: IARC; 2016. p. 259-85.

33. Chaux A, Pfannl R, Rodriguez IM, Barreto JE, Velazquez EF, Lezcano C, Piris A Netto GJ, Cubilla AL. Distinctive immunohistochemical profile of penile intraepithelial lesions: a study of 74 cases. Am J Surg Pathol. 2011;35(4):553-62.

\section{Submit your next manuscript to BioMed Central and we will help you at every step:}

- We accept pre-submission inquiries

- Our selector tool helps you to find the most relevant journal

- We provide round the clock customer support

- Convenient online submission

- Thorough peer review

- Inclusion in PubMed and all major indexing services

- Maximum visibility for your research

Submit your manuscript at www.biomedcentral.com/submit
) Biomed Central 